Document downloaded from:

http://hdl.handle.net/10251/48022

This paper must be cited as:

Ribeiro, C.; Panadero Pérez, JA.; Sencadas, VJGDS.; Lanceros Mendez, S.; Tamaño Machiavello, MN.; Moratal Pérez, D.; Salmerón Sánchez, M.... (2012). Fibronectin adsorption and cell response on electroactive poly (vinylidene fluoride) films. Biomedical Materials. 7(3):35004-35014. doi:10.1088/1748-6041/7/3/035004.

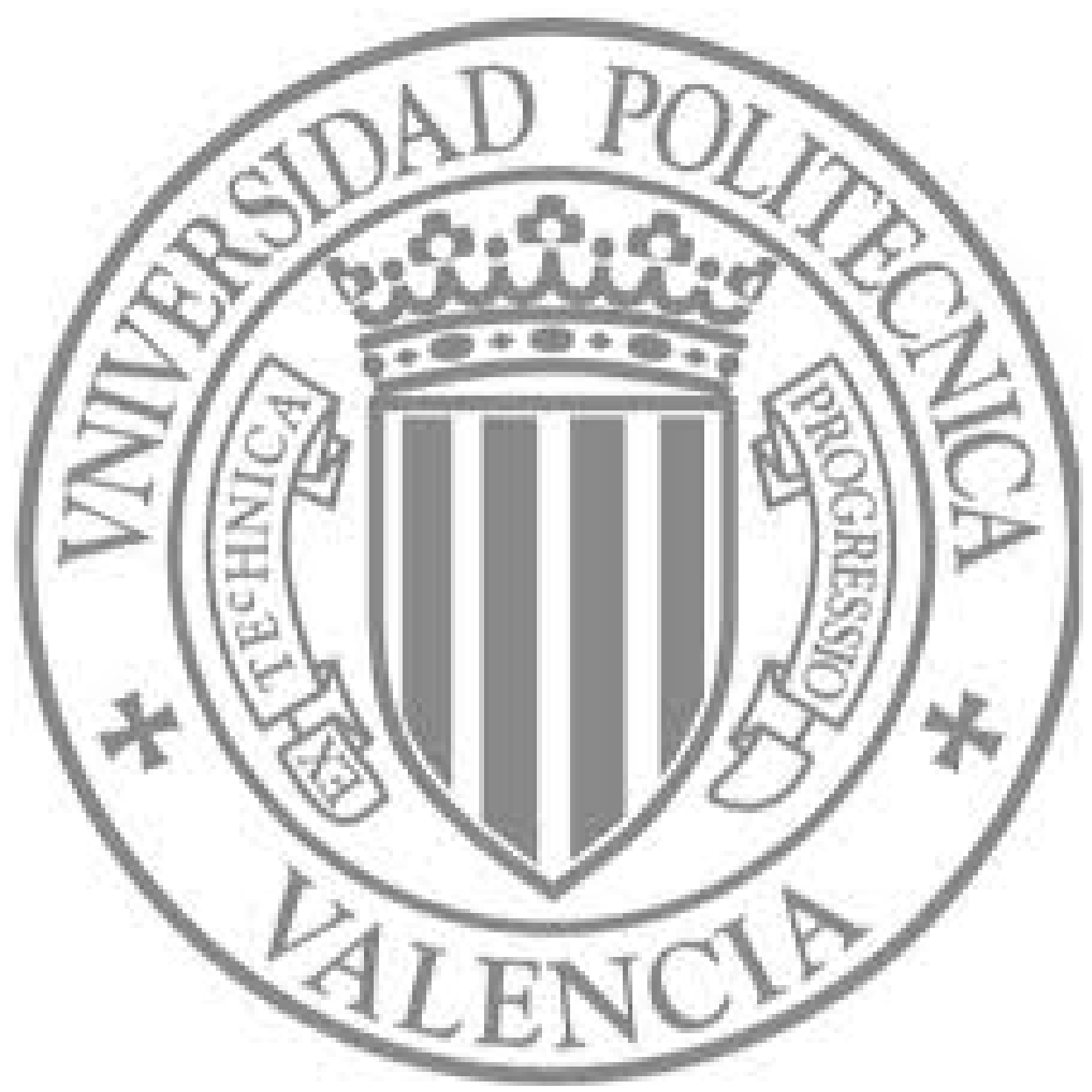

The final publication is available at

http://dx.doi.org/10.1088/1748-6041/7/3/035004

Copyright

IOP Publishing: Hybrid Open Access 


\title{
Fibronectin adsorption and cell response on electroactive poly(vinylidene fluoride) films
}

\author{
C. Ribeiro ${ }^{1}$, J.A. Panadero ${ }^{1}$, V. Sencadas ${ }^{1}$, S. Lanceros-Méndez ${ }^{1, *}$, M.N. \\ Tamaño $^{2}$, D. Moratal ${ }^{2}$, M. Salmerón-Sánchez ${ }^{2,3,4}$, J.L. Gómez \\ Ribelles $^{2,3,4}$
}

1 Center/Departament of Physics, University of Minho, Campus de Gualtar, 4710-057 Braga, Portugal

2 Center for Biomaterials and Tissue Engineering, Universidad Politécnica de Valencia, Camino de Vera s/n, 46022 Valencia, Spain

3 Prince Felipe Research Center, Autopista del Saler 16, 46013 Valencia, Spain 4 Networking Research Center on Bioengineering, Biomaterials and Nanomedicine (CIBER-BBN), Valencia, Spain

*lanceros@fisica.uminho.pt

\begin{abstract}
Due to the large potential of electroactive materials in novel tissue engineering strategies, the aim of this work is to determine if the crystalline phase and/or the surface electrical charge of electroactive poly(vinylidene fluoride), PVDF, have influence on the biological response in monolayer cell culture. Non-polar $\alpha$-PVDF and electroactive $\beta$-PVDF were prepared. The $\beta$-PVDF films were poled by corona discharge to show negative or positive electrical surface charge density. It has been concluded that hydrophilicity of the PVDF substrates depends significantly on crystalline phase and polarity. Further, by means of AFM and ELISA test it has been shown that positive or negative poling strongly influences the behaviour of $\beta$-PVDF supports with respect to fibronectin adsorption, varying the exhibition of adhesion ligands of adsorbed fibronectin. Culture of MC3T3-E1 pre-osteoeblasts proved that cell proliferation depends on surface polarity as well. These results open the viability of cell culture stimulation by mechanical deformation of a piezoelectric substrate that results in varying electrical charge densities on the substrate surface.
\end{abstract}

PACS: 82.35.Pq; 87.85.J-; 77.84.-s; 87.17.-d 
Keywords: Poly(vinylidene fluoride); fibronectin; piezoelectric; MC3T3-E1 preosteoeblasts

\section{Introduction}

In the last decades, a wide variety of biomaterials with different properties have been studied and developed for biomedical applications. The cell/biomaterial interaction is a complex multi-step process that consists of several events. The first observable event in vivo or in a culture medium in vitro is the adsorption of proteins [1-2]. Then, cell adhesion is mediated by cell-surface receptors that interact with specific ligands recognized in the layer of proteins previously adsorbed on the biomaterial surface [3-4]. This protein layer is then reorganized and substituted by matrix proteins produced by the cells [5-7]. The quality of this first phase of cell/biomaterial interactions will influence the ability of the cells for proliferation and differentiation [8-9].

The adsorption of matrix proteins such as fibronectin (FN) on substrate surfaces has been shown to be of large importance when culturing a variety of cells in vitro [10-11]. The activity of adsorbed proteins (i.e. the distribution, concentration, conformation and motility) plays an important role in the biofunctionality of the biomaterial and allows understanding the biological response in cell culture in the laboratory $[4,10]$. The surface characteristics such as chemical composition, topography, viscoelastic properties, electric charge distribution and others determine how biological molecules will be absorbed by the surface and, more particularly, it will also determine the conformation of adsorbed molecules [8, 12]. In this way, the behavior of cells cultured on substrates is highly dependent on these characteristics.

Previous studies have shown that electrically charged surfaces can influence cell behavior in different aspects such as growth, adhesion or morphology of cells. Beyond this, an electrically charged base for tissue engineering applications can be an interesting and promising approach [13]. Electroactive polymers, in particular piezoelectric polyvinylidenefluoride (PVDF), have attracted interest for biomedical applications in the fabrication of sensors and actuators and supports for cell culture. PVDF shows good biocompatibility, chemical resistance, and, in particular, excellent 
electroactive properties, such as piezo-, pyro-, and ferroelectricity [14]. This polymer can be obtained in four different crystalline phases, known as $\alpha, \beta, \gamma$ and $\delta$, depending on the processing conditions. The $\beta$-phase is the one with the best piezoelectric and pyroelectric properties [14-15].

The processing conditions optimizing the electroactive properties of $\beta$-PVDF have been previously studied both for films obtained from solvent evaporation [16-17] and for films obtained by mechanical stretching [18-19]. Particularly relevant for the present work are previous studies by scanning force microscopy in a piezoresponse mode on the variations in the topological morphology and piezoelectric surface response of PVDF [20]. The piezoelectric activity at a mesoscale reflects the semicrystalline nature of the polymer: the piezoelectric activity of the $\beta$-phase at a mesoscopic scale is formed by dispersed nanoregions instead of classical domains. Clear differences in the poled region distribution and size, as well as in the local piezoactivity, have been identified in the different forms of PVDF: in the poled $\beta$-PVDF samples, the piezoelectric activity is more evident than before poling, the piezoelectric activity of $\beta$-PVDF being independent of the processing method and morphology. No local piezoelectric activity is obtained in $\alpha$-PVDF, corresponding to the nonpolarity of the macromolecule and the absence of macroscopic piezoelectric response.

Due to the potential of electroactive materials in the biological and biomedical field, as they respond to electrical and mechanical solicitations, the aim of this work is to understand the role of the crystalline phase and polarity (i.e. surface charge) of electroactive supports on the cell response. With this purpose, the polymer with the largest electroactive response, $\beta$-phase PVDF, is investigated. As a first step fibronectin from human plasma was adsorbed on the different PVDF films from solutions of varying protein concentration. The surface density of adsorbed FN was quantified by the enzyme linked immunosorbent assay (ELISA) technique and the protein distribution and conformation was observed by Atomic Force Microscopy (AFM). Thereafter, the effect of polymer phase ( $\alpha$ or $\beta$ ) and surface polarization on preosteoblasts morphology, viability and proliferation was studied.

\section{Materials and Methods}




\subsection{Preparation of polymer films}

Poly(vinylidene fluoride) films with thickness of around $30 \mu \mathrm{m}$ were obtained by casting a 20\% solution of PVDF (Solef 1010 from Solvay) in $\mathrm{N}, \mathrm{N}$-dimethyl formamide (DMF) on a glass slide, applying the procedure reported in [16, 18]. Briefly, a glass slide with the spread solution was kept inside an oven at a controlled temperature of $120^{\circ} \mathrm{C}$ for $60 \mathrm{~min}$ in order to assure the removal of the solvent and the isothermal crystallization of PVDF. After evaporation of the solvent, the sample was melted at 220 ${ }^{\circ} \mathrm{C}$ for $10 \mathrm{~min}$. Then, the samples were removed from the oven, cooled to room temperature and removed from the glass. The polymer obtained by this procedure is predominantly $\alpha-P V D F$. These films were then uniaxially drawn in a tensile machine at a stretching velocity of $\sim 1 \mathrm{~mm} / \mathrm{min}$ at a temperature of $80{ }^{\circ} \mathrm{C}$ and a draw ratio $(\mathrm{R}=$ $\left.\mathrm{L}_{\text {fnal }} / \mathrm{L}_{\text {initial }}\right)$ of 5 . After this procedure, the $\beta$-phase content of the samples is maximised up to $\sim 85 \%$ [18-19]. The $\alpha$ to $\beta$ phase transformation is accompanied by a morphological transition from a spherulitic microstructure typical of the $\alpha$ - PVDF to a microfibrilar microstructure [18].

The electrical poling of the $\beta$-PVDF films was performed by a corona discharge inside of a home-made chamber and the piezoelectric response $\left(d_{33}\right)$ of the poled samples was analyzed with a wide range $d_{33}$-meter (model 8000, APC Int Ltd). The obtained value of the piezoelectric $\mathrm{d}_{33}$ coefficient for the poled samples was $\sim-32 \mathrm{pC} / \mathrm{N}[16]$.

For cell culturing, circular PVDF films with $11 \mathrm{~mm}$ diameter were cut from the prepared films and sterilized by immersing several times in 70\% ethanol for $15 \mathrm{~min}$. Before cell seeding, the samples were washed 5 times for $5 \mathrm{~min}$ in phosphate-buffered saline (PBS) solution.

The films used in this study were $\alpha$-PVDF, non-poled $\beta$-PVDF, "poled +" $\beta$-PVDF (cell culture on the positively charged side of the sample) and "poled -" $\beta$-PVDF (cell culture on the negatively charged side of the sample).

\subsection{Contact angle measurements}

The contact angle measurements (sessile drop in static mode) were performed at room temperature in a Data Physics OCA 20 device using distilled water as test liquid. All the micrographs were taken at the same focal distance $(20 \mathrm{~cm})$ and the volume of the drops was of $20 \mu \mathrm{l}$. The contact angles were determined after six repetitions for each sample by using an image analysis software (Image J) taking into account the entire drop shape. 


\subsection{Fibronectin adsorption}

FN distribution on the different substrates was observed by Atomic Force Microscopy. Fibronectin from human plasma (Sigma) was adsorbed on the different PVDF films $(\alpha-$ PVDF, non-poled $\beta$-PVDF, "poled +" $\beta$-PVDF and "poled -" $\beta$-PVDF) by immersing the material sheets in FN solutions with different concentrations $\left(1,2\right.$ and $\left.5 \mu \mathrm{g} \cdot \mathrm{mL}^{-1}\right)$ in modified saline $(0.4 \% \mathrm{NaCl})$ for $10 \mathrm{~min}$. After protein adsorption, the samples were rinsed in saline solution to eliminate the non-adsorbed protein. After that, the samples were dried by exposing their surface to a nitrogen flow for a few minutes. AFM experiments were performed in tapping mode in air immediately after sample preparation, using a Multimode AFM equipped with NanoScope IIIa controller from Veeco (Manchester, UK), at ambient conditions. Si-cantilevers with a constant force of $2,8 \mathrm{~N} / \mathrm{m}$ and a resonance frequency of $75 \mathrm{kHz}$ were used. All the samples were characterized using a set-point amplitude ratio of around 0.9. The NanoScope 5.30r2 software version was used for the simultaneous recording of the height, phase and amplitude magnitudes of the images.

FN conformation was characterized by ELISA using monoclonal antibodies directed to cell adhesion domains. FN was adsorbed on all samples from a solution of $5 \mu \mathrm{g} \cdot \mathrm{mL}^{-1}$ for $1 \mathrm{~h}$ at $37^{\circ} \mathrm{C}$. The same samples without FN were used as controls. After FN adsorption, the surfaces of PVDF films were washed a few times in Dulbecco's Phosphate Buffered Saline solution (DPBS) to remove non-adsorbed protein. After the FN adsorption, the nonspecific binding sites of the PVDF surface were blocked with DPBS++/BSA $1 \%$ for $30 \mathrm{~min}$ at room temperature. Then, the samples were incubated in the presence of monoclonal antibody IgG1 (DSHB University of Iowa), directed against the synergic site, in the $\mathrm{FN}$ repeat $\mathrm{III}_{9}$, in dilution $1: 4000$ for $1 \mathrm{~h}$ at $37^{\circ} \mathrm{C}$. Following the incubation, each substrate was washed a few times with DPBS++/Tween 20. After being rinsed, a secondary antibody, antimouse alkaline phosphatase (Jackson Immuno Research), in dilution 1:5000 was added to the PVDF substrates for $1 \mathrm{~h}$ at $37^{\circ} \mathrm{C}$ and then washed again as described above. The 4-methylumbelliferyl phosphate (4MUP; Sigma) was added to the samples for $45 \mathrm{~min}$ at $37^{\circ} \mathrm{C}$. The optical density (absorbance) of the wells at a wavelength of $465 \mathrm{~nm}$ was measured using a standard plate reader (Victor III, Perkin Elmer). Each experiment was performed in triplicate. 


\subsection{Cell Adhesion and overall morphology}

MC3T3-E1 cells (Riken cell bank, Japan) were cultivated in Dulbecco's modified Eagle's medium (DMEM) 1g/L glucose (Gibco) containing 10\% Fetal Bovine Serum (FBS) (Fisher) and $1 \%$ penicillin/streptomycin $(\mathrm{P} / \mathrm{S})$ at $37^{\circ} \mathrm{C}$ in $\mathrm{CO}_{2}$ incubator. To investigate the initial cell adhesion and overall cell morphology, osteoblast-like cells suspended in $400 \mu \mathrm{L}$ of serum-free DMEM were seeded on the substrates (PVDF samples disks and control glass covers) in 24-well TC plates at a cell density of $1 \times 10^{4}$ cells/well. All samples (three repetitions per sample) were previously coated with FN $\left(20 \mu \mathrm{g} . \mathrm{mL}^{-1}\right)$ for $1 \mathrm{~h}$ at $37^{\circ} \mathrm{C}$. After $2 \mathrm{~h}$ of incubation, the cells were rinsed with DPBS and fixed with formalin solution 10\%, neutral buffered (Sigma-Aldrich) (1h at $4^{\circ} \mathrm{C}$ ). After that, the substrates were washed with DPBS, permeabilized with Triton X-100 (5 min at room temperature) and incubated with a monoclonal mouse antibody against vinculin (Sigma-Aldrich) (1:400 in 1\% DPBS/BSA, at room temperature for $1 \mathrm{~h}$ in agitation). The samples were rinsed a few times with $0.5 \%$ DPBS/Tween 20 . Thereafter, it was added Alexa Fluor 633-conjugated rabbit anti-mouse secondary antibody (Invitrogen) (1:200 in 1\% DPBS/BSA, at room temperature for $1 \mathrm{~h}$ in agitation) and, at the same time, Bodipy FL Phallacidin (Invitrogen) for actine cytoskeleton $(10 \mu \mathrm{L} /$ sample). At last, the substrates were washed with $0.5 \%$ DPBS/Tween 20 and mounted with Vectashield containing DAPI. Focal adhesions were visualized by immune-fluorescence staining of vinculin. Images of adhered cells were taken with a fluorescence microscope (Leica DM6000B). Cytoplasma observed by cytoskeleton images were processed and analyzed using an in house software developed under MATLAB R2009b (The MathWorks, Inc., Natick, MA, USA). Mean cell area was calculated for every sample.

To determine the area covered by each cell, the processing of the cytoplasm images consisted firstly in grayscaling and equalization. Afterwards, the images were binarized using the Otsu's method [21] and the existing gaps were filled using an erosion morphological operator followed by a dilation one, using both a diamond structuring element of size 3 . The resulting image was size-filtered using an opening morphological operator to eliminate remaining isolated pixels. In this way, a binary image stating the cytoplasm coverage was obtained, allowing the calculation of the total area covered by the cells or the mean area covered by each cell. 


\subsection{Cell viability and proliferation}

For the study of cell viability and proliferation, the cells were seeded in 24-well TC plates with PVDF films and glass covers used as control at a cell density of $10^{4}$ cells/well for 3 days and 7 days, and incubated at $37^{\circ} \mathrm{C}$ and $5 \% \mathrm{CO}_{2}$. All samples (three repetitions for each sample) were previously immersed in a fibronectin solution $20 \mu \mathrm{g} \mathrm{mL} L^{-1}$ for $1 \mathrm{~h}$ at $37^{\circ} \mathrm{C}$. After washing all samples with DPBS, cells were suspended in DMEM without serum and seeded in the samples for $2 \mathrm{~h}$ at $37{ }^{\circ} \mathrm{C}$ and $5 \% \mathrm{CO}_{2}$. Finally, medium was replaced with DMEM containing 10\% FBS.

For the quantification of cell viability and proliferation, MTS (3-(4,5-dymethylthiazol2-yl)-5-(3-carboxymethoxyphenyl)-2(4-sulfopheny)-2H tetrazolium) assay (CellTiter $96^{\mathrm{TM}}$ Aqueous One Solution Cell Proliferation Assay, Promega) was carried out. In this assay, the samples were washed a few times with DPBS. Then, $600 \mu \mathrm{L}$ of MTS solution (prepared with DMEM-LG without FBS, in a relation 1:5) was added to the substrates and it was incubated for $3 \mathrm{~h}$ at $37{ }^{\circ} \mathrm{C}$ in a $5 \% \mathrm{CO}_{2}$ incubator. At the end of the incubation period, $100 \mu \mathrm{L}$ of each sample were transferred (in triplicate) into a 96 well-plate. Finally, the absorbance at $490 \mathrm{~nm}$, representing the proportion of viable cells, was measured by an optical spectrometer (Victor III, Perkin Elmer).

For cell number quantification, after fixation with a formalin buffered solution, the cell -supports constructs were mounted with Vectashield containing DAPI for fluorescence microscopy (Leica DM6000B). For cell counting, the previously described software was used. Cell nuclei images were firstly grayscaled and equalized, providing an output grayscale image with its intensity values evenly distributed throughout the intensity range. These new images were then binarized through the Otsu's method and sizefiltered using an opening morphological operator. The cell nuclei were finally labeled and counted. Thus, cell number per $\mathrm{mm}^{2}$ was calculated.

\subsection{Statistical Analysis}


The results were expressed in mean \pm standard deviation. Statistical comparisons were made by analysis of variance (ANOVA) and F-tests were used for the evaluation of different groups. The differences were considered significant when $\mathrm{p}<0.05$.

\section{3 .Results}

\subsection{Contact angle measurements}

Surface wettability (generally referred to as hydrophobicity/hydrophilicity) is one of the most important parameters affecting the biological response. According to the literature, wettability affects protein adsorption and cell adhesion [22-23]. The wettability of the different PVDF film surfaces was determined showing that (Figure 1) the non-poled $\beta$ PVDF film is the more hydrophobic, with a contact angle of $76.8^{\circ}$, significantly higher than that measured in $\alpha$-PVDF. Corona treatment produces an increase of the wettability of the $\beta$-PVDF films surface. The "poled +" $\beta$-PVDF film is the most hydrophilic material with a contact angle of $31.8{ }^{\circ} \mathrm{C}$, lower than that of the negatively charged surface.

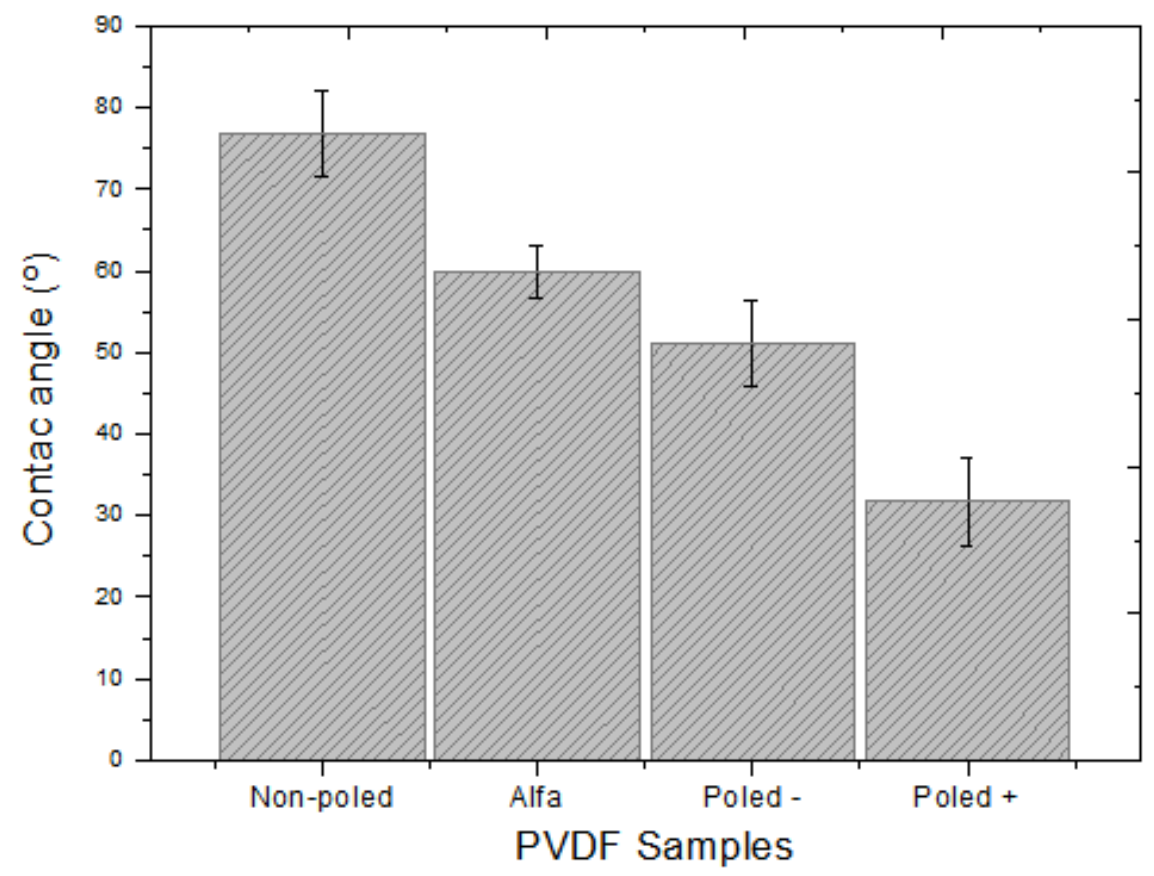

Fig. 1 - Evaluation of water contact angle of different PVDF films (Alfa, Beta nonpoled, poled + and poled -). 


\subsection{Surface topography}

The processing conditions of PVDF influence the phase content, morphology and electroactivity [20]. PVDF adopts an spherulitic morphology in the $\alpha$ phase [15], that can be observed in the AFM pictures (Figure $2 \mathrm{a}, \mathrm{b}$ ). Crystal lamellae are apparent both in amplitude and phase images. The $\alpha-P V D F$ is a non-electroactive phase and the mean roughness measured in $2 \times 2$ microns surface areas (average of 3 measurements) was around $68.5 \mathrm{~nm}$. The topography of $\beta$-PVDF is quite different, being characterized by an oriented microfibrilar microstructure [18] (Figure $2 \mathrm{c}, \mathrm{d}$ ). When the $\beta$-PVDF sample is poled there are no significant differences in morphology. With the AFM analysis of the local piezoresponse data of the non-poled $\beta$-PVDF and poled samples, it is shown [20] that a clear piezoresponse signal exists in both samples, being therefore the domain contrast more pronounced in the poled samples. The mean roughness of the non-poled $\beta-P V D F$ is approximately $42 \mathrm{~nm}$. The poling process does not affect the topography of the samples which maintain the same mean roughness [20]. The analysis of the line profiles of the topographic image and the corresponding domain contrast image confirm that there is no relationship between the surface piezoelectric response and the topography [20]. 

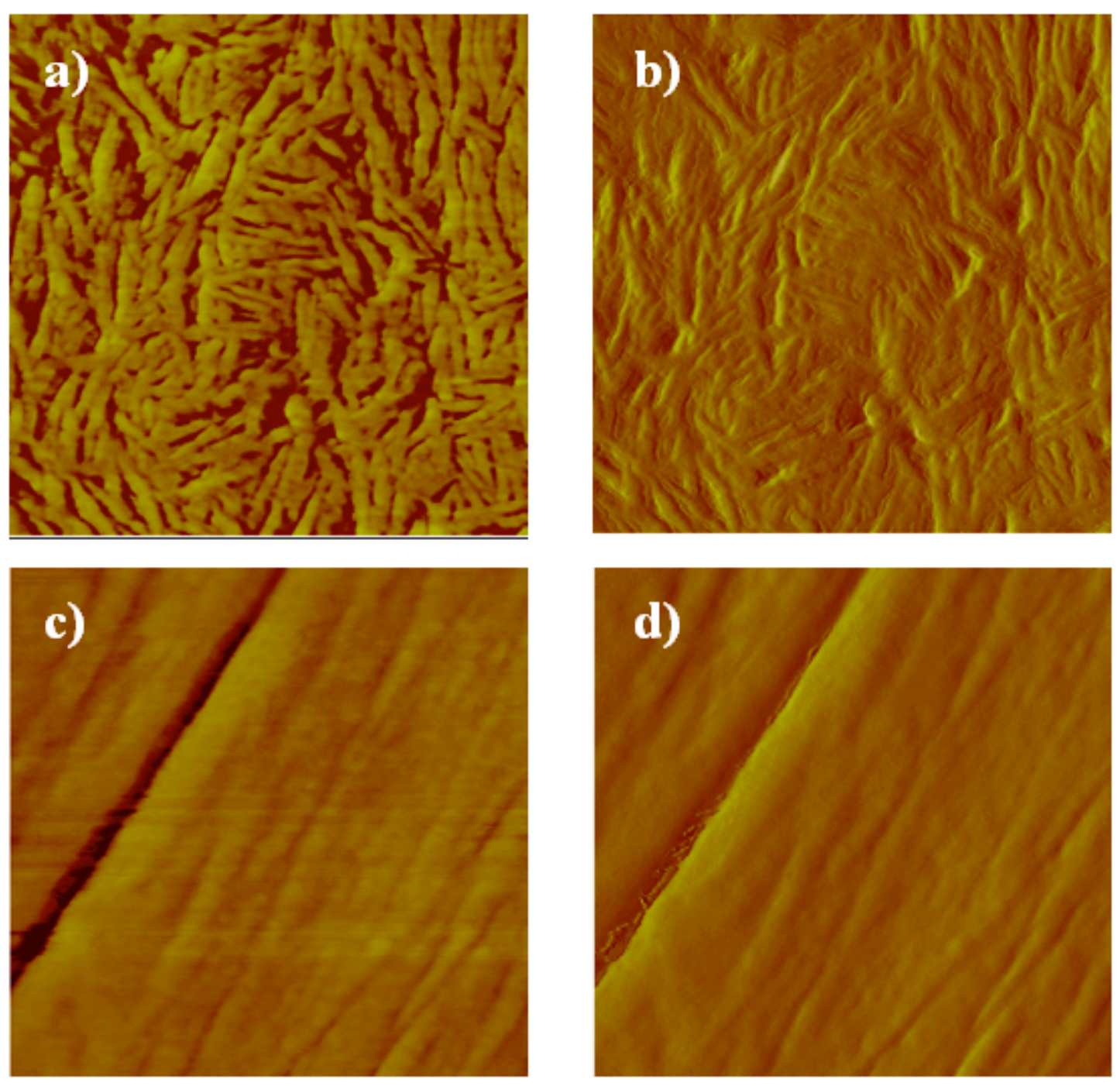

Fig. 2 - AFM images recorded in a $1 \times 1 \mu \mathrm{m}$ area of $\alpha$-PVDF $(a, b)$ and non-poled $\beta$ PVDF (c, d) surfaces. Phase (a, c) and amplitude (b, d) pictures are shown.

\subsection{Protein adsorption}

The distribution of fibronectin adsorbed on the substrate can be observed by AFM provided the surface density of protein molecules is low enough. If the amount of protein adsorbed is too high, a continuous coating is formed preventing the observation of single protein molecules as well as their distribution at the material interface. This is the reason why FN was adsorbed on the substrates from aqueous solutions of varying concentration. Figure 3 shows AFM images (height, phase and amplitude) of non-poled $\beta$-PVDF films after FN adsorption from a $2 \mu \mathrm{g} \cdot \mathrm{mL}^{-1}$ solution. 


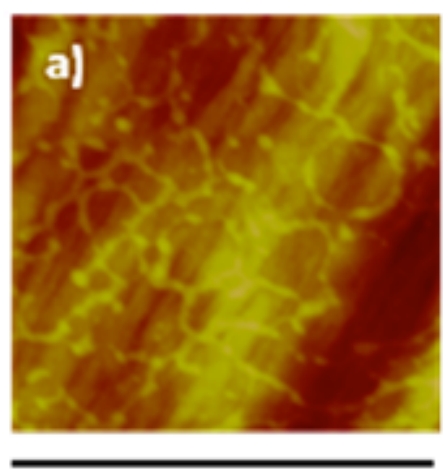

$1 \mu \mathrm{m}$

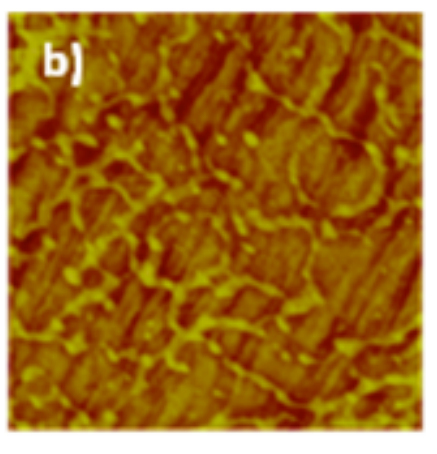

$1 \mu \mathrm{m}$

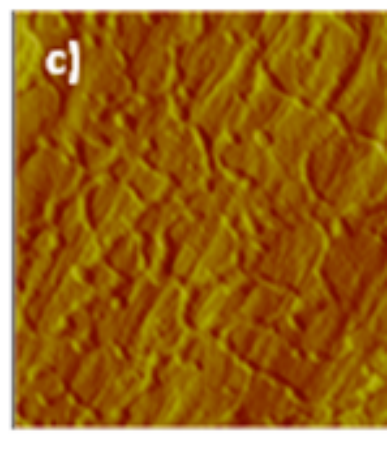

$1 \mu \mathrm{m}$

Fig. 3 - AFM images of non-poled $\beta$-PVDF with fibronectin adsorbed form a solution with a concentration of $2 \mu \mathrm{g} \cdot \mathrm{mL}^{-1}$. a) Height, b) phase and c) amplitude magnitudes respectively.

Figure 4 shows the AFM images of the adsorbed proteins on the different PVDF films. FN distribution and organization on the surface depends significantly on the type of substrate and the concentration of the protein solutions.

The influence of the crystalline phase of the polymers is quite apparent when comparing $\alpha$-PVDF and non poled $\beta$-PVDF films. In both cases at the lower solution concentrations $\left(1-2 \mu \mathrm{g} \cdot \mathrm{mL}^{-1}\right)$, homogeneously distributed FN molecules on the substrates are observed. When FN was adsorbed from a $2 \mu \mathrm{g} \cdot \mathrm{mL}^{-1}$ solution, a well defined fibrillar distribution is found on $\beta$-PVDF, with the incipient formation of a protein network. On the other hand, a more homogeneous FN distribution is found on $\alpha$ PVDF. Higher concentration of the FN solution $\left(5 \mu \mathrm{g} \cdot \mathrm{mL}^{-1}\right)$ gives rise to the formation of a FN continuous protein coating that, in the case of $\alpha$-PVDF, completely covers the spherulitic topography of the polymer. Likewise, $\alpha$ - and $\beta$-PVDF surfaces display similar appearance when they are completely covered by the protein layer.

In the poled $\beta$-PVDF films, the situation is quite different: a dense coating is formed already when $\mathrm{FN}$ is adsorbed from the $1 \mu \mathrm{g} \cdot \mathrm{mL}^{-1}$ solution. By increasing FN concentration, some changes in the topography of the protein surface are observed with no observable differences between the "poled +" and "poled -" $\beta$-PVDF substrates. 


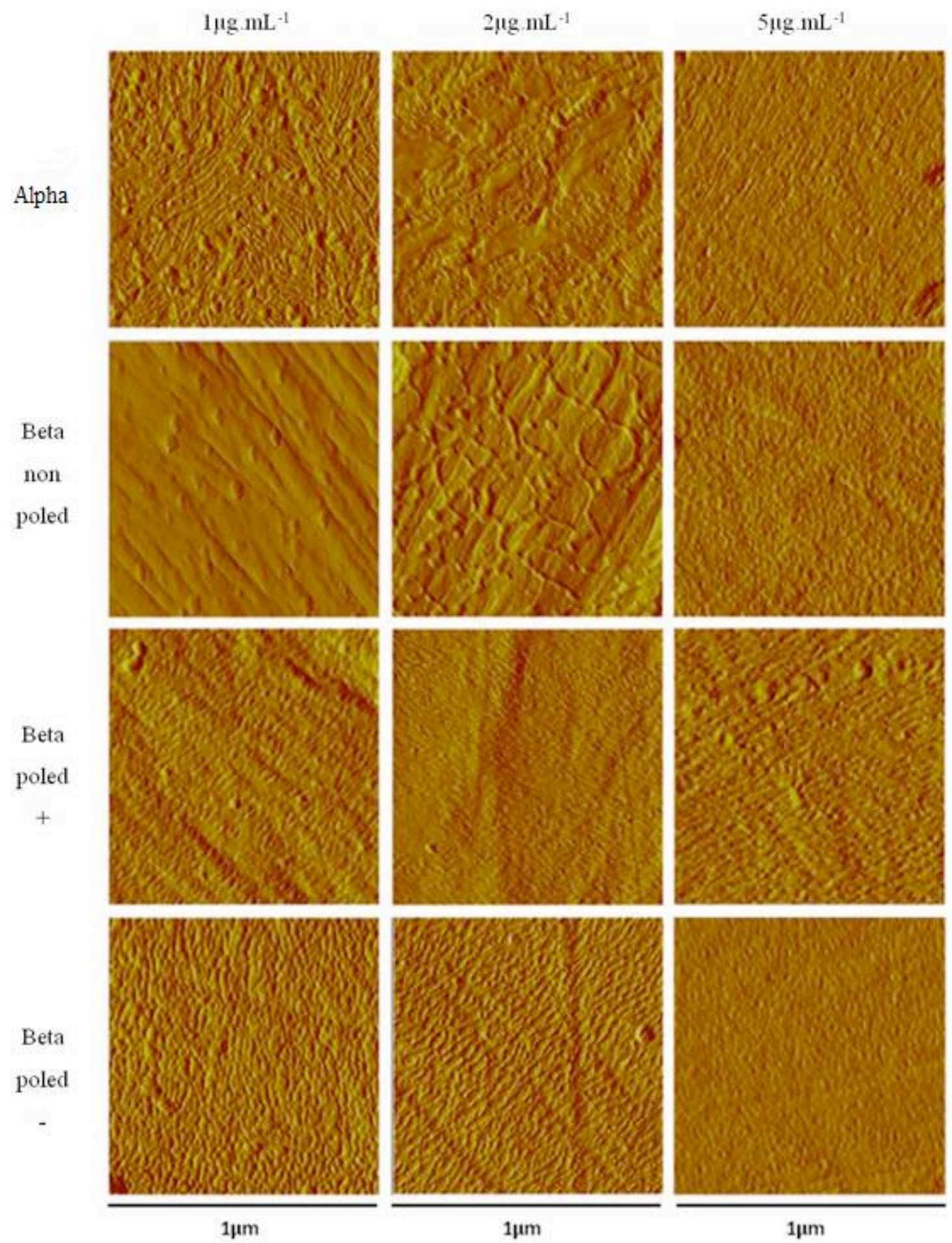

Fig. 4 - Fibronectin distribution as observed by the amplitude magnitude in AFM on the different substrates $(\alpha-\mathrm{PVDF}, \beta-\mathrm{PVDF}$ non poled, "poled +" $\beta$-PVDF and "poled -“ $\beta$ PVDF). Fibronectin was adsorbed for 10 min from solutions of different concentrations $\left(1 \mu \mathrm{g} \mathrm{mL}^{-1}, 2 \mu \mathrm{g} \mathrm{mL} \mathrm{L}^{-1}, 5 \mu \mathrm{g} \mathrm{mL}{ }^{-1}\right)$. 
Single molecules could not be distinctly observed by AFM even in smaller scans areas. However, it can be inferred from FN adsorption from solution of concentration 2 $\mu \mathrm{g} \mathrm{mL} \mathrm{m}^{-1}$ that approximately the same amount of $\mathrm{FN}$ is adsorbed on the different surfaces. Further, the differences in protein distribution observed at the lower concentrations suggest surface-induced changes in FN conformation [24]. Thus, an ELISA assay was performed to quantify differences in FN conformation, using antibodies against adhesion related domains, in order to obtain information about domain exposition. Figure 5 shows the results of the ELISA experiments for the different PVDF films and the control substrate. These results confirm that adhesion domains in poled $\beta$-PVDF films are more available for cell adhesion than in either non poled $\beta$-PVDF or $\alpha$-PVDF films. These domains are significantly masked in non poled $\beta$-PVDF. Nevertheless, the difference between positively or negatively charged surfaces is not significant.

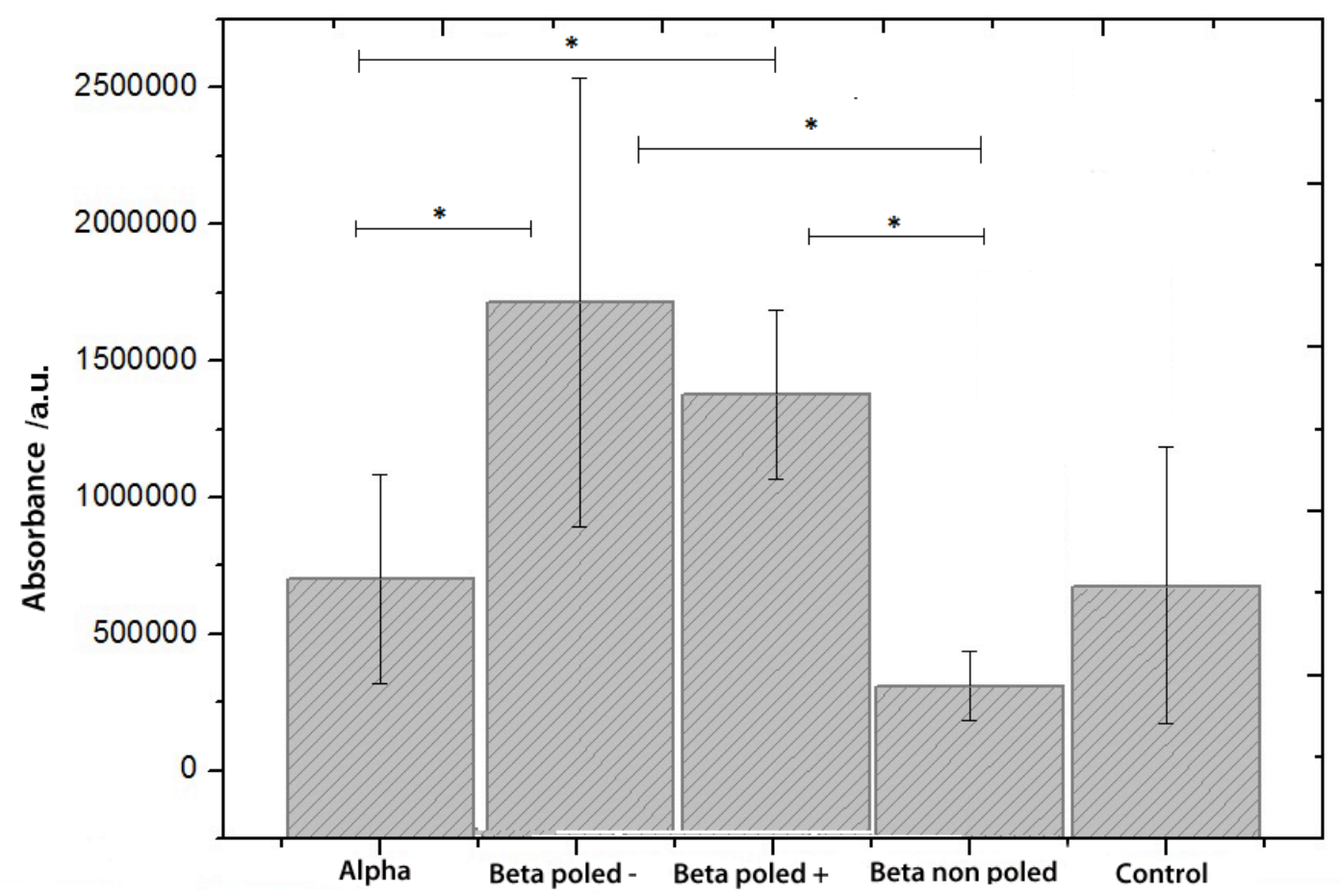

Fig. 5 - Monoclonal antibody binding for HFN7.1 monoclonal antibody on the different PVDF samples after FN adsorption from a solution of concentration $5 \mu \mathrm{g} / \mathrm{mL}$.

* Significantly different $(\mathrm{p}<0.05)$ PVDF samples. 


\subsection{Cell attachment and cell proliferation}

The overall morphology of the cells after $2 \mathrm{~h}$ is observed in Figure 6 . With respect to cell morphology and cell area, no significant differences were detected between poled and non-poled films, as well as between films in different phases and the control glass.
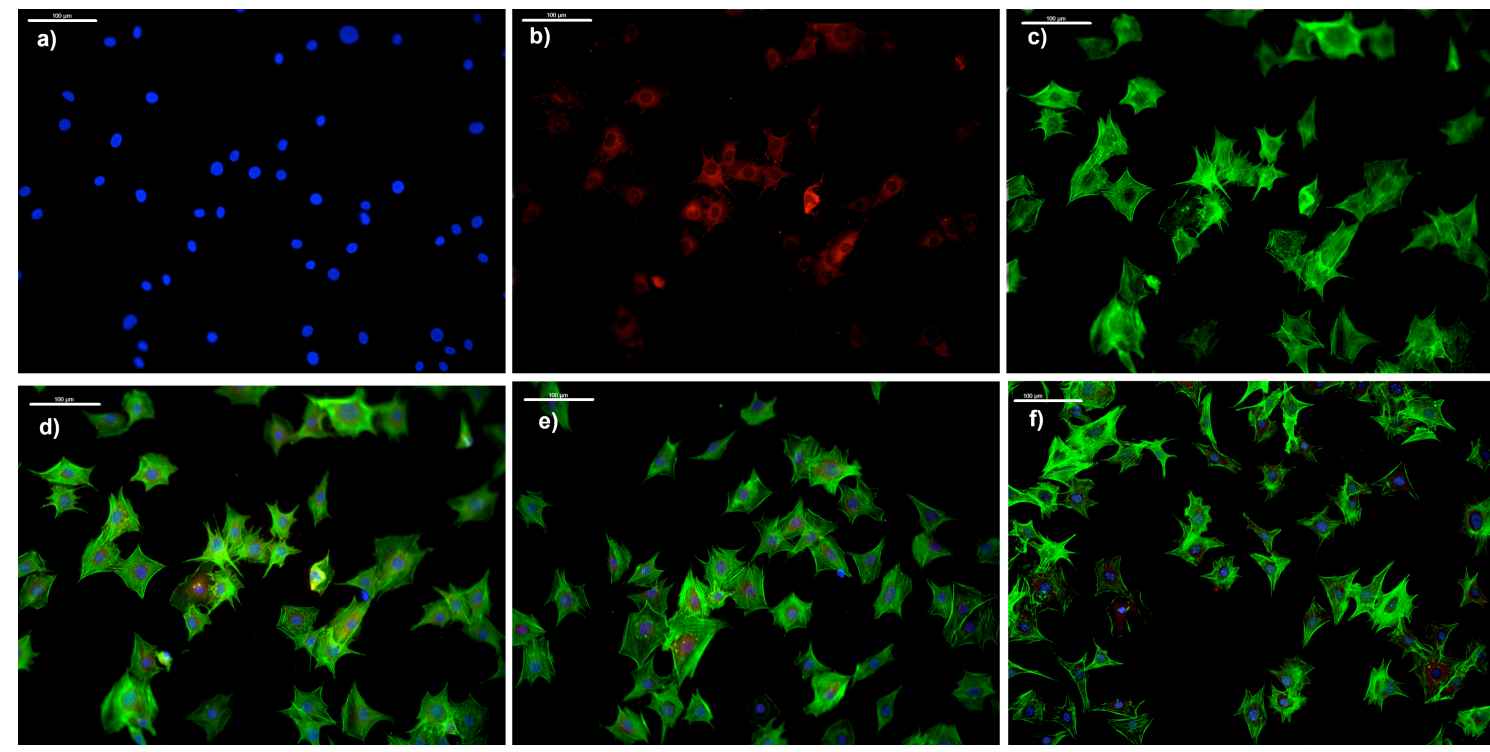

Fig. 6 - Cell culture with pre-osteoblast cells during 2 hours in negative poled $\beta$-PVDF film (DAPI stained nuclei are shown in (a), vinculin expression in (b) and F-actin staining in (c), overlay (d)) For comparison the overlay images of $\alpha$-PVDF film and control glass are shown in (e) and (f) respectively. The scale bar $(100 \mu \mathrm{m})$ is valid for all the images.

Figure 7 shows the viability of the attached osteoblast cells in PVDF films and control after 3 and 7 days of culture. For all substrates, the number of viable cells increased with cell culture time. The substrates that seem to promote more active proliferation are $\alpha$-PVDF and both positive and negative poled $\beta$-PVDF films, with no significant differences with respect to the control and among them. Cell viability is significantly lower in the case of non poled PVDF as shown by the MTS test. Nevertheless, when cell nuclei were stained with DAPI and counted from fluorescence microscopy images no significant differences in cell density between poled and non-poled $\beta$-PVDF substrates was found (Figure 8). 
The shapes of the cells attached on the different substrates are quite similar to each other and also similar to the control, as shown in Figure 6. Cells are extended on the substrates and form well defined and developed actin cytoskeleton. Using image analysis, the average surface covered by a cell was found to be $4475 \pm 349 \mu \mathrm{m}^{2}$ with no significant differences among the substrates.

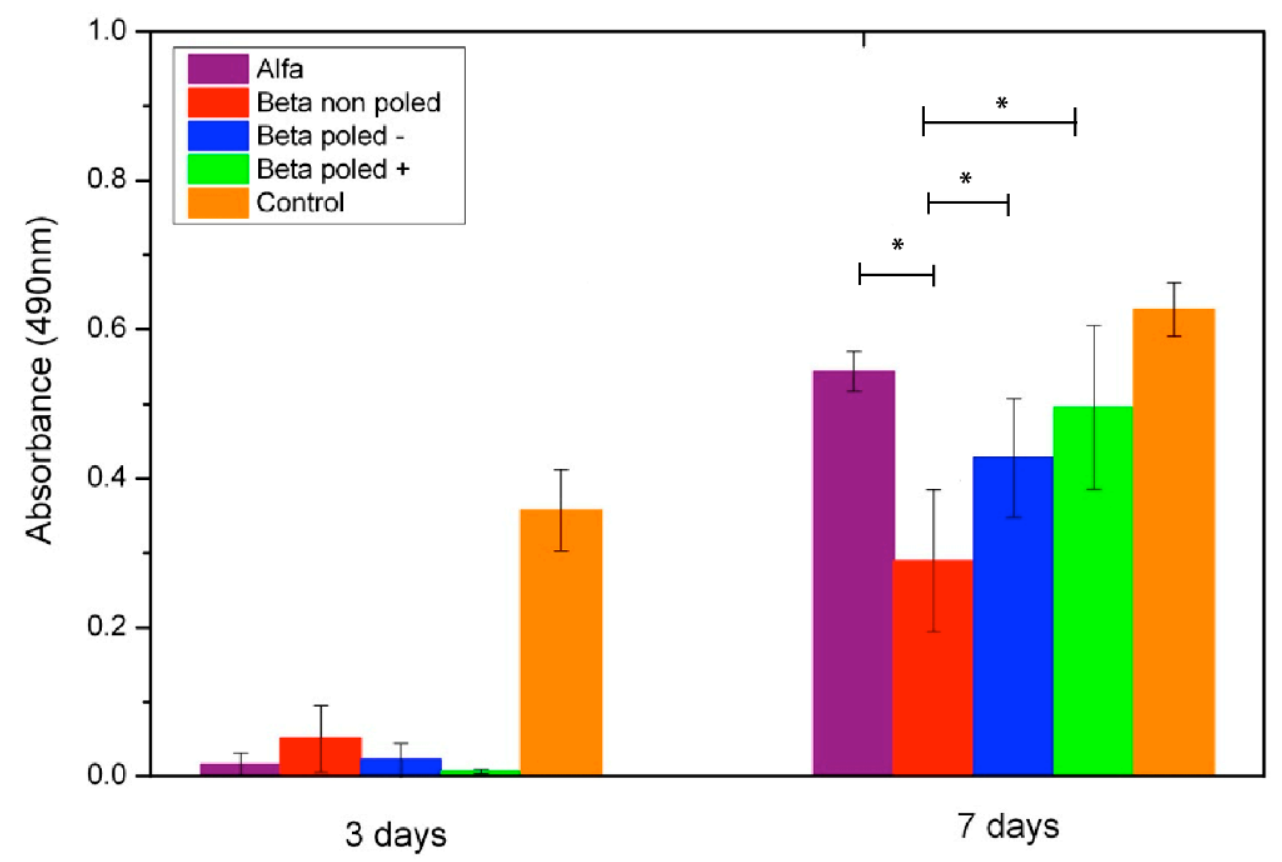

Fig. 7 - MTS absorbance results after cells seeded for 3 and 7 days on different PVDF films and control substrate. * Significantly different $(\mathrm{p}<0.05)$ PVDF samples.

Cell density on the different substrates is represented in Figure 8. After 3 days, all samples show low number of cells. After 7 days of cell culture, the samples show significant differences in the number of cells. Also, it can be also observed that the cell distribution in the samples is not uniform. The control substrate shows the highest number of cells $/ \mathrm{mm}^{2}$, but comparing just the different PVDF films, the non poled $\beta$ PVDF films show the lowest cell number and the poled $\alpha$-PVDF films the highest number, with no significant differences with both poled $\beta$-PVDF, positive and negative . 


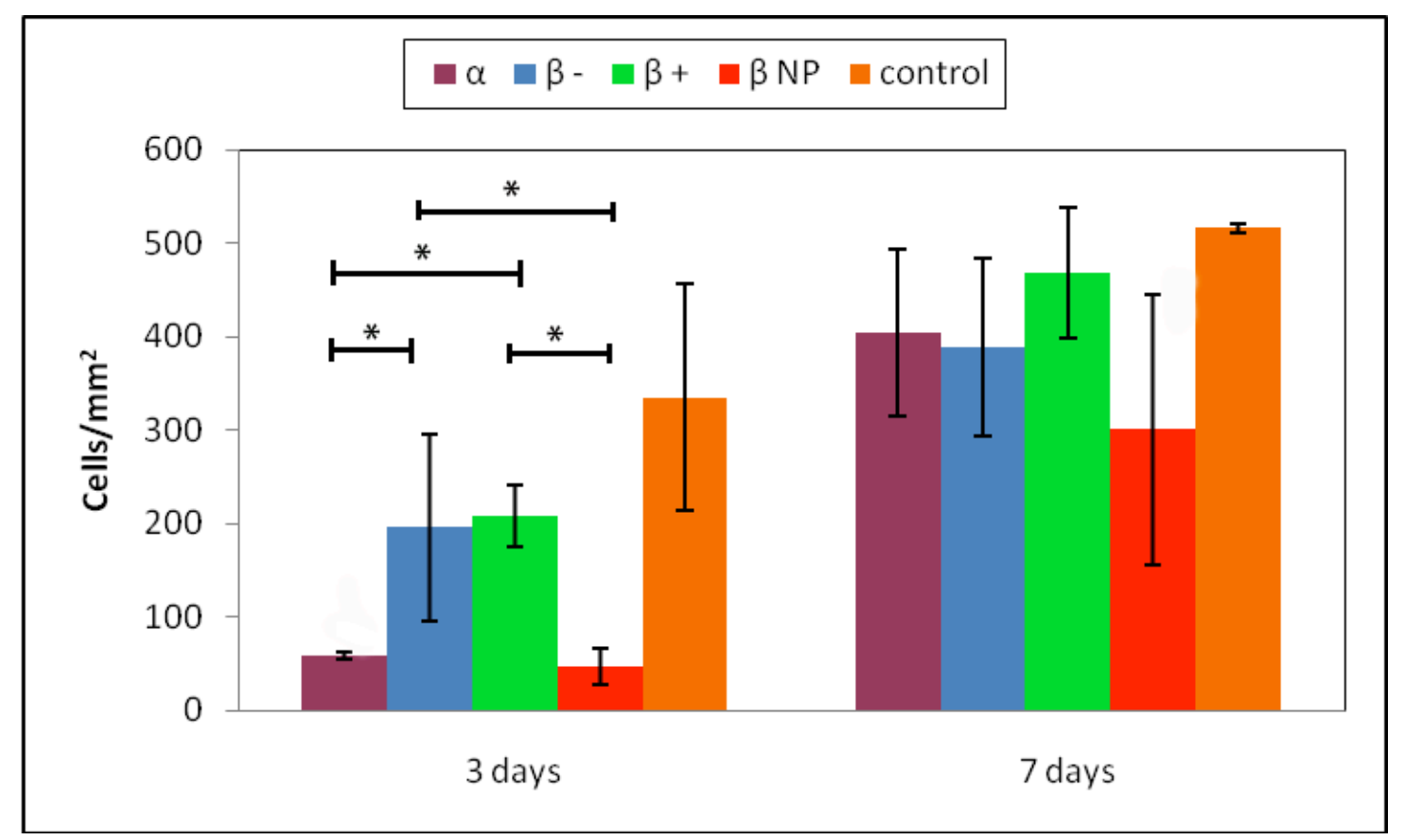

Fig. 8. Cell density after for 3 and 7 days on different PVDF films and control substrate. * Significantly different $(\mathrm{p}<0.05)$ PVDF samples.

\section{Discussion}

The surface properties of PVDF are influenced by its crystalline phase, not only because of the different arrangement of crystal lamellae that, as shown in Figure 2, leads to a different roughness and surface topography, but also due to a different surface energy leading to a quite hydrophobic material in the case of non poled $\beta$-PVDF and to a more hydrophilic one in the case of $\alpha-P V D F$. The reason for these differences is related to the different ordering of the permanent dipoles along the polymer chains in one and another crystalline order. The configuration of PVDF chains crystallized in $\alpha$ phase is a nonpolar trans-gauche-trans-gauche', TGTG', configuration, leading the consecutive permanent dipoles of the monomer units to orient in opposite directions, resulting in no net dipole per unit cell $[14,25]$. The crystalline $\beta$-phase has an all trans planar zigzag configuration, TTT, which confers to this crystalline phase the highest resulting 
permanent dipolar moment and consequently the best electroactive properties $[14,25]$. Notice nevertheless, that the non-poled $\beta$-phase PVDF shows a random distribution of the dipolar moments, and therefore, the overall surface charge will be zero. Just by poling the samples and alignment of the dipolar moments and an overall surface distribution will be achieved [20]

FN adsorption has been studied on different synthetic substrates. A straightforward correlation between substrate hydrophilicity and FN adsorption does not exist since other surface properties such as surface chemistry [26-27], the presence of particular functional groups [28], roughness or the presence of patterning cues [27], have also an important effect on FN adsorption. While many studies have shown that larger amounts of protein adsorbs on hydrophobic surfaces than on hydrophilic ones, as it is the case with other matrix proteins as laminin, fibrinogen or vitronectin [29-30], the literature also shows many important examples of higher activity of FN on hydrophilic surfaces [31-32]. On the other hand, the conformation of FN on the substrate is also highly influenced by other surface characteristics. It seems that an important characteristic of FN with respect to cell adhesion is its ability to intermolecular linkage forming a fibrillar structure (fibrillogenesis) or a protein network. Cell activity seems to be essential for fibrillogenesis but it has been observed in some synthetic substrates in absence of cells. This is the case of hydrophobous poly(ethyl acrylate) substrates [3334].

When the electroactive $\beta$-PVDF is poled by corona discharge, introducing a positive or negative electric charge density, the wettability of the surface increase significantly as shown in Figure 1.

In the PVDF substrates of this work the observed behavior by adsorbed fibronectin is peculiar in some aspects. Although the AFM images of Figure 4 give no quantitative information about protein adsorption, they suggest that adsorbed protein quantity is higher in poled $\beta$-PVDF than in non poled $\beta$-PVDF or in $\alpha$-PVDF but only when adsorbed from low FN concentration solutions. When FN is adsorbed from a $5 \mu \mathrm{g} \mathrm{ml}^{-1}$, the FN layer observed in all samples looks similar. When dispersed protein domains are observed, the images suggest differences in distribution. The visual aspect in non-poled $\beta$-PVDF is clearly different than in $\alpha$-PVDF when immersed in the same FN solution. 
Association in fibrils seems to appear only in non-poled $\beta$-PVDF, which can be related to the lower hydrophilicity of its surface. Randomly distributed FN aggregates can be observed in $\alpha$-PVDF or in the poled samples at very low FN concentration.

Data from the ELISA experiments complement the information obtained from the AFM images. ELISA experiments were performed on samples after adsorption from a $5 \mu \mathrm{g} . \mathrm{mL}^{-1}$ FN solution in which the surface appearance in AFM is that of a homogeneous coating of the PVDF surface (Figure 4). The exposition of cell adhesion domains is significantly higher in the poled $\beta$-PVDF samples with respect to non poled samples and also with respect to the control. It seems that the presence of a surface distribution of electric charges overcomes the effect of other surface properties. On the one hand exposition of adhesion ligands in poled samples is higher than in non-poled $\beta$ PVDF, that shows the same topography, despite the later having much lower wetability. In the same way, it is higher than in $\alpha$-PVDF.

MC3T3-E1 pre-osteoblasts were seeded on the substrates previously coated with fibronectin and in a culture medium in absence of serum in order to avoid the modification of the protein layer adsorbed on the substrate. In order to allow long-term culture, medium with FBS was added after initial adhesion. Cells adhere to all the substrates, develop focal adhesions and organize the actin cytoskeleton. The shape of the cells and the average surface covered per cell for the shortest times of cell culture seems to be equal in the four substrates under study. Some of the differences in MC3T3-E1 pre-osteoblasts are just shown after several days of culture and are in accordance with the differences shown in protein adsorption and conformation. The low absorbance in MTS experiments at three days culture does not allow us to detect significant differences among the different samples due to the small signal, the absorbance being much lower than in the control surface. Nevertheless, the cell numbers counted from fluorescence microscope images clearly show that cell numbers are higher in the poled $\beta$-PVDF samples what correlates with availability of cell adhesion sequences of the adsorbed fibronectin, as determined by ELISA tests. At seven days culture the cell number and MTS absorbance in non-poled $\beta$-PVDF sample seems still to be smaller than in the samples with a surface density of electric charges. MC3T3-E1 
are highly proliferative cells, reaching confluence in few days in tissue culture polystyrene or in the glass slides used as controls in our experiments. This is shown by the high cell numbers and MTS signal after 3 days culture in the controls in contrast with the slower culture proliferation in all the PVDF substrates. Nevertheless, after relatively short times of culture cells reach confluence in all substrates and at 7 days culture the cell numbers and MTS signal tends to be the same in the $\alpha$ and positively or negatively poled $\beta$-PVDF samples and also nearly the same as that of the controls. Only non-poled $\beta$-PVDF shows significantly smaller MTS absorbance and small mean cell numbers than the rest culture surfaces at day 7. For longer culture time this sample shows the same cell number than the others.

These experiments show that the presence of electrical charge on the surface of the piezoelectric material influence the distribution and conformation of adsorbed protein layers on the material surface and in turn on cell adhesion. In this sense it is particularly significant the difference between poled and non-poled states of the electroactive $\beta$ phase of PVDF. If this material is deformed by the action of mechanical forces, the piezoelectric effect will produce the variation of the electrical charge density at the interfaces with the biological tissue. Thus, this type of substrate can be used for simultaneous mechanical and electric stimulation of cells in culture.

\section{Conclusions}

It is shown that polarization of a PVDF electroactive crystalline phase to create both a negative or positive electrical charge surface density modifies the conformation of adsorbed fibronectin at the material surface and therefore cell adhesion on the FNcoated substrates. As a consequence, cell numbers on the substrate are significantly higher in poled than in non-poled samples. Differences in fibronectin adsorption between $\alpha$ and non-poled $\beta$ crystalline phases due to different surface topography, wettability and ordering of polymer chain groups are detectable but can be considered less important. In this way, these results open the possibility of developing active substrates for cell culture and tissue engineering, influencing cell response through variation of the surface electrical charge density when a mechanical solicitation is applied. 


\section{Acknowledgements}

This work is funded by FEDER funds through the "Programa Operacional Factores de Competitividade - COMPETE" and by national funds by FCT- Fundação para a Ciência e a Tecnologia, project reference NANO/NMed-SD/0156/2007. C. R. thanks the INL for a $\mathrm{PhD}$ grant. V.S. and J.A.P. thank the FCT for the SFRH/BPD/63148/2009 and SFRH/BD/64586/2009/ grants, respectively. JLGR acknowledge the support of the Spanish Ministry of Education through project No. MAT2010-21611-C03-01 (including the FEDER financial support), project EUI2008-00126, and funding in the Centro de Investigación Principe Felipe in the field of Regenerative Medicine through the collaboration agreement from the Conselleria de Sanidad (Generalitat Valenciana), and the Instituto de Salud Carlos III (Ministry of Science and Innovation). The authors thank Armando Ferreira for the help with the contact angle measurements and CENTI, Portugal, for allowing the use of the set-up.

\section{References}

[1] Ratner BD. Biomaterials science : an introduction to materials in medicine. Amsterdam; Boston: Elsevier Academic Press; 2004.

[2] Shard AG, Tomlins PE. Biocompatibility and the efficacy of medical implants. Regenerative Medicine 2006;1:789-800.

[3] Klee D, Ademovic Z, Bosserhoff A, Hoecker H, Maziolis G, Erli HJ. Surface modification of poly(vinylidenefluoride) to improve the osteoblast adhesion. Biomaterials 2003;24:3663-70.

[4] Guerra NB, Gonzalez-Garcia C, Llopis V, Rodriguez-Hernandez JC, Moratal D, Rico P, et al. Subtle variations in polymer chemistry modulate substrate stiffness and fibronectin activity. Soft Matter 2010;6:4748-55.

[5] Altankov G, Groth T. Reorganization of substratum-bound fibronectin on hydrophilic and hydrophobic materials is related to biocompatibility. Journal of Materials Science: Materials in Medicine 1994;5:732-7.

[6] Avnur Z, Geiger B. The removal of extracellular fibronectin from areas of cellsubstrate contact. Cell 1981;25:121-32. 
[7] Altankov G, Groth T, Krasteva N, Albrecht W, Paul D. Morphological evidence for a different fibronectin receptor organization and function during fibroblast adhesion on hydrophilic and hydrophobic glass substrata. Journal of Biomaterials Science. Polymer Edition, 1997; 8: 721-740.

[8] Anselme K. Osteoblast adhesion on biomaterials. Biomaterials 2000;21:667-81.

[9] Wilson CJ, Clegg RE, Leavesley DI, Pearcy MJ. Mediation of biomaterial-cell interactions by adsorbed proteins: A review. Tissue Engineering 2005;11:1-18.

[10] Whittle JD, Bullett NA, Short RD, Douglas CWI, Hollander AP, Davies J. Adsorption of vitronectin, collagen and immunoglobulin-G to plasma polymer surfaces by enzyme linked immunosorbent assay (ELISA). Journal of Materials Chemistry 2002;12:2726-32.

[11] Barrias CC, Martins MCL, Almeida-Porada G, Barbosa MA, Granja PL. The correlation between the adsorption of adhesive proteins and cell behaviour on hydroxylmethyl mixed self-assembled monolayers. Biomaterials 2009;30:307-16.

[12] Okada S, Ito H, Nagai A, Komotori J, Imai H. Adhesion of osteoblast-like cells on nanostructured hydroxyapatite. Acta Biomaterialia 2010;6:591-7.

[13] Weber N, Lee YS, Shanmugasundaram S, Jaffe M, Arinzeh TL. Characterization and in vitro cytocompatibility of piezoelectric electrospun scaffolds. Acta Biomaterialia 2010;6:3550-6.

[14] Lovinger AJ. Developments in crystalline polymers. London: Elsevier Applied Science; 1982.

[15] Nalwa HS. Ferroelectric polymers: chemistry, physics and applications. New York: Marcel Dekker, Inc.; 1995.

[16] Branciforti MC, Sencadas V, Lanceros-Mendez S, Gregorio R. New technique of processing highly oriented poly(vinylidene fluoride) films exclusively in the beta phase. Journal of Polymer Science Part B-Polymer Physics 2007;45:2793-801.

[17] Sencadas V, Gregorio Filho R, Lanceros-Mendez S. Processing and characterization of a novel nonporous poly(vinilidene fluoride) films in the [beta] phase. Journal of Non-Crystalline Solids 2006;352:2226-9.

[18] Sencadas V, Gregorio R, Lanceros-Mendez S. alpha to beta Phase Transformation and Microestructural Changes of PVDF Films Induced by Uniaxial Stretch. Journal of Macromolecular Science Part B-Physics 2009;48:514-25. 
[19] Gomes J, et al. Influence of the $\beta$-phase content and degree of crystallinity on the piezo- and ferroelectric properties of poly(vinylidene fluoride). Smart Materials and Structures 2010;19:065010.

[20] Nunes JS, Wu A, Gomes J, Sencadas V, Vilarinho PM, Lanceros-Mendez S. Relationship between the microstructure and the microscopic piezoelectric response of the alpha- and beta-phases of poly(vinylidene fluoride). Applied Physics a-Materials Science \& Processing 2009;95:875-80.

[21] Otsu N. Threshold selectino method from gray-level histograms. IEEE Trans Syst Man Cybern 1979;9:62-6.

[22] Sigal GB, Mrksich M, Whitesides GM. Effect of surface wettability on the adsorption of proteins and detergents. Journal of the American Chemical Society 1998;120:3464-73.

[23] Vanwachem PB, Beugeling T, Feijen J, Bantjes A, Detmers JP, Vanaken WG. Interaction of cultured human-endothelial cells with polymeric surfaces of different wettabilities. Biomaterials 1985;6:403-8.

[24] Hernandez JCR, Sanchez MS, Soria JM, Ribelles JLG, Pradas MM. Substrate chemistry-dependent conformations of single laminin molecules on polymer surfaces are revealed by the phase signal of atomic force microscopy. Biophysical Journal 2007;93:202-7.

[25] Bar-Cohen Y. Electroactive Polymer (EAP) Actuators as Artificial Muscles Reality, Potential, and Challenges, 2004: 89-120, (2nd Edition). SPIE.

[26] Roach P, Eglin D, Rohde K, Perry C. Modern biomaterials: a review-bulk properties and implications of surface modifications. Journal of Materials Science: Materials in Medicine 2007;18:1263-77.

[27] Tsapikouni TS, Missirlis YF. Protein-material interactions: From micro-to-nano scale. Materials Science and Engineering: B 2008;152:2-7.

[28] Michael KE, Vernekar VN, Keselowsky BG, Meredith JC, Latour RA, García AJ. Adsorption-Induced Conformational Changes in Fibronectin Due to Interactions with Well-Defined Surface Chemistries. Langmuir 2003;19:8033-40.

[29] Schmidt DR, Waldeck H, Kao WJ. Protein Adsorption to Biomaterials Biological Interactions on Materials Surfaces. In: Puleo DA, Bizios R, editors.: Springer New York; 2009. p. 1-18. 
[30] Comelles J, Estévez M, Martínez E, Samitier J. The role of surface energy of technical polymers in serum protein adsorption and MG-63 cells adhesion. Nanomedicine : nanotechnology, biology, and medicine 2010;6:44-51.

[31] Garcia AJ, Vega MD, Boettiger D. Modulation of cell proliferation and differentiation through substrate-dependent changes in fibronectin conformation. Mol Biol Cell 1999; 10:785-98.

[32] Llopis-Hernandez V, Rico P, Ballester-Beltran J, Moratal D, Salmeron-Sanchez M. Role of Surface Chemistry in Protein Remodeling at the Cell-Material Interface. PLoS One $2011 ; 6$.

[33] Salmeron-Sanchez M, Rico P, Moratal D, Lee TT, Schwarzbauer JE, Garcia AJ. Role of material-driven fibronectin fibrillogenesis in cell differentiation. Biomaterials 2011;32:2099-105.

[34] Gugutkov D, Gonzalez-Garcia C, Hernandez JCR, Altankov G, Salmeron-Sanchez M. Biological Activity of the Substrate-Induced Fibronectin Network: Insight into the Third Dimension through Electrospun Fibers. Langmuir 2009;25:10893-900. 